\title{
UNA APROXIMACIÓN A LA CUESTIÓN DE LA PATERNIDAD DE M. BRUTO POR PARTE DE CÉSAR EN LA OBRA DE SIR RONALD SYME ${ }^{1}$
}

\author{
AN APPROACH TO THE MATTER OF M. BRUTUS' PATERNITY \\ BY CAESAR IN THE OEUVRE OF SIR RONALD SYME
}

\section{Mikel GAGO GÓMEZ DE LUNA²}

RESUMEN: El objetivo de este trabajo es estudiar la celebérrima y controvertida cuestión de la paternidad de M. Bruto por parte de J. César en la obra de R. Syme, así como los antecedentes y la recepción de la visión del historiador oxoniense en esta materia. A tal fin, comenzaremos realizando una contextualización del tema sobre el que versa el escrito acusando la existencia de un cambio ostensible en el interés de Syme sobre César a partir de 1960. Seguidamente, efectuaremos un análisis de los trabajos del investigador neozelandés en los que se interesó por la cuestión de la paternidad César-Bruto propiamente dicha; llevaremos a cabo un ejercicio de retrotracción a fin de comentar el panorama historiográfico relativo a esta polémica previo a Syme; y, por último, nos haremos eco también de las investigaciones que, posteriores a la del gran profesor británico, han retomado este interesante aspecto.

PALABRAS CLAVE: Ronald Syme. Julio César. Marco Bruto. Paternidad. Historiografía. Historia de Roma.

ABSTRACT: The goal of this work is to study the celebrated and controversial issue of the paternity of M. Brutus by J. César in the work of R. Syme, including the precedents and the reception of the oxonian historian's vision in this matter as well. To get this, we will start by contextualizing the subject of the writing revealing the existence of an perceptible change in the interest of Syme on Caesar since 1960.

\footnotetext{
${ }^{1}$ He de expresar mi más sincero agradecimiento a A. Duplá Ansuategui (UPV/EHU) y a Gustavo A. Vivas García (ULL) por la importantísima ayuda prestada para la realización de este trabajo. Huelga añadir que todo yerro presente es responsabilidad mía.

${ }^{2}$ Universidad del País Vasco/Euskal Herriko Unibertsitatea (UPV/EHU). Programa de Doctorado en Ciencias de la Antigüedad. E-mail: gagomikel@gmail.com. ORCID ID: 000-0001-8192-0105.
} 
Next, we will make an analysis of the New Zealand researcher's works in which he was interested by the issue of Caesar-Brutus's paternity properly said; we will carry back in time in order to discuss about the historiographical outlook related to this controversy previous to Syme; and, finally, we will also examine the investigations which, after the great British professor, have taken this interesting aspect up.

KEYWORDS: Ronald Syme. Julius Caesar. Marcus Brutus. Paternity. Historiography. Roman History.

\section{LA ESPECIOSA INALTERABILIDAD DE LA OBRA DE R. SYME Y EL CONSECUENTE CAMBIO EN SU VISIÓN SOBRE CÉSAR}

En 1961, Arnaldo Momigliano escribía que R. Syme se cuidó mucho siempre de hacer declaraciones teóricas, confesiones autobiográficas y que, por ello, siempre fue reacio a dar explicaciones de sí mismo, y concluía de todo ello que "il suo sviluppo intelletuale resta oscuro per me"3. Más de dos décadas después, L. Canfora, por su parte, señalaba que Syme era muy avaro en las indiscreciones acerca de su propia formación ${ }^{4}$. A pesar de que Momigliano escribía en el ecuador de la carrera de Syme y Canfora tan solo algo después, momentos ambos en los que un balance de la carrera del autor neozelandés in toto podría haber resultado algo prematuro, recientemente W. V. Harris, a casi 30 años vista de la muerte de Syme, ha apuntado que "Syme was a private, indeed secretive, person who saw no reason to explain himself".

Estas reflexiones captan mucho mejor que algunas otras, por ejemplo de G. Alföldy ${ }^{6}$, sin discusión uno de los mejores conocedores de la obra de Syme, de S. Demougin ${ }^{7}$ o incluso de su propio discípulo, E. Badian, cuando pretendía resumir toda la obra de Syme con la palabra "prosopografía", la verdadera naturaleza de la visión histórica de Syme9. Representan, en el terreno más personal, la imagen de un Syme especioso, cambiante, oscuro, en última instancia difícilmente asible. En este sentido, probablemente hubiese "muchos Syme", y con toda seguridad el profesor oxoniense no fuera jamás un plano, sino un poliedro, y, por tanto, según incidiese el rayo de luz en una cara, un vértice o una arista de este poliedro, el arco que reflejaba fuera vario, complejísimo y de múltiples colores.

\footnotetext{
3 Momigliano, 1962: x.

${ }^{4}$ CANFORA, 1991: 198.

5 HARRIS, 2017.

${ }^{6}$ Alföldy, 1979: 168 y 177-179; contra ArCE, 1994: 46-47 y 2010: XIII-XIV; SCHEID, 2000. Acerca de la producción de Alföldy sobre Syme, resultan especialmente útiles VIVAS, 2012 y 2017.

7 Demougin, 2000: 102-103; contra VIVAS, 2016: 176; HARris, 2017.

${ }^{8}$ BADIAN, 1979: xii; contra Millar, 1981: 148.

${ }^{9}$ Habida cuenta de que hemos hablado sobre todo esto en otro lugar (GAGO, en prensa), bosquejaremos únicamente los trazos más fundamentales.
} 
Por ello, como se viene apuntando, es indiscutible la existencia de una suerte de retractatio por parte de Syme en función de sus trabajos más tardíos ${ }^{10}$, hasta el punto de que T. P. Wiseman ha hablado de un "late Syme", en el sentido de un cambio en los planteamientos del autor neozelandés a partir de los años $60^{11}$; todo esto a despecho de que Alföldy apunte que el cambio es menos importante que la continuidad a lo largo de la producción académica de Syme ${ }^{12}$.

Pero además existió un "Syme público" y un "Syme privado". Sabemos que el primero desdeñaba, por aburrimiento o por convicción teórica -si es que Syme realmente se valía de cuestiones teóricas y de método-, dedicar estudios a la plebe y a los estratos inferiores en general ${ }^{13}$, y abominaba de la biografía ${ }^{14}$, sobre todo aquella consagrada a César ${ }^{15}$. El segundo, en cambio, en función de trabajos inéditos que recientemente se han ido publicando o se conocen provenientes de su Nachlass, llegó a estar interesado por cuestiones como la composición étnica del populus romano, las mujeres, la plebe y la dimensión socioeconómica de la transición de la República al Principado -quizá influenciado, especula F. Santangelo, por los entonces recientes estudios de P. A. Brunt- ${ }^{16}$; y en última instancia, no pudiendo escapar de la fascinación por la personalidad de Julio César ${ }^{17}$, tenemos constancia de que los últimos años de su vida Syme se hallaba entregado a la escritura de una monografía de carácter biográfico intitulada Caesar que jamás pudo finalizar ${ }^{18}$.

Pues bien, es precisamente en el campo del interés de Syme por César donde se aprecia, como ya hemos mostrado en el otro trabajo mencionado ${ }^{19}$, una evolución ostensible. A partir de 1960 observamos un giro en la producción de Syme sobre César que se traduce, en primer lugar, en un inusitado interés por investigar los posibles vástagos de César: Syme rechaza las propuestas de Cesarión y de M. Bruto ${ }^{20}$, pero se inclina por proponer la de D. Bruto, figura por la que, además, experimen-

\footnotetext{
10 WALTER, 2002; cfr. SYME, 1988.

11 WISEMAN, 1998.

12 AlFÖldY, 1979: 179.

${ }^{13}$ SYME, 1939: 7 y 476; 1958: v y 1986: 13; cfr. AlFÖLDY, 1983: 17; ARCE, 2010: XII-XIII y 2017.

14 SYME, 1939: 7 y 1971: 40.

15 SYME, 1985: 12; 1988: 64.

16 SANTANGELO, 2014 y 2016: 10-11.

17 " [...] he could not escape the fascination of Caesar's personality: he saw him as a dandy in dress, a pedant about language, and a rigorous purist, and remarked, 'such persons may be intolerably despotic; he was an expert on religious ritual and loved ceremony - a kind of ancient "AngloCatholic»'” (GRIfFIN, 2009: 8 y cfr. 2005: 31). El fragmento que cita la Profa. M. Griffin pertenece al susodicho manuscrito biográfico sobre César. M. Toher es, sin embargo, el autor de la investigación que más en profundidad se ha hecho sobre el inédito Caesar. Se trata de una conferencia finalmente no publicada que dictó en The Florida State University, en el marco de los Langford Latin Seminar, coloquio celebrado entre el 1 y el 3 de 2001.

18 BiRLEY, 1999: xix; GRIFFIN, 2005: 30-32 y 2009: 8; SANTANGELO, 2016: 11-12.

19 Gago, en prensa.

${ }^{20}$ SYME, 1960: 323-327; 1980: 422-437 y 1986: 18.
} 
tará un inusitado interés, fundamentalmente por su cursus honorum junto a César, y a la que ahora otorgará un papel más importante en la trama de los idus de marzo hasta el punto de considerarlo la clave para comprender y ejecutar el complot ${ }^{21}$. En segundo lugar, observamos un acercamiento con carácter shakesperiano a César, quien ahora se antoja al profesor oxoniense "a tragic failure"22; y, en tercer lugar advertimos una aproximación, aunque intermitente, al género biográfico, del que hasta entonces había abominado, así como a la ficción tras sopesar profundamente las demandas de la creatividad histórica ${ }^{23}$. En este trabajo vamos a limitarnos principalmente a abordar el interés de Syme por la cuestión de la paternidad entre César y M. Bruto.

Resulta absolutamente desconcertante que la producción sobre la visión de César que tuvo el "late Syme" se halle tan poco estudiada. La inmensa mayoría se ha centrado fundamentalmente en la honda impresión que generaron sus estudios de finales de la década de los treinta y que culminaron en el -como reconoció G. W. Bowersock en aquel bautismo de Syme como "The Emperor of Roman History"- tremendo impacto de su seminal The Roman Revolution ${ }^{24}$, y que versaron sobre otros aspectos diferentes de los que el autor neozelandés desarrollará a partir de 1960, como las últimas intenciones de César, los senadores y el "partido" del dictador, la supresión de la memoria de César durante el reinado de Augusto, etc. ${ }^{25}$ Por ejemplo, un especialista en la historiografía sobre el propio Julio César como sin duda lo fue Z. Yavetz, a la hora de realizar un pormenorizado recorrido sobre lo que del gran potentado romano se había escrito desde el s. XIX hasta sus propios días, dedica en sus trabajos espacio para el César del "early Syme", ubicándolo en el colectivo que él califica como "The Minimalists", pero no parece importarle la interesante visión que sobre Julio César arroja el profesor neozelandés a partir de la década de los sesenta ${ }^{26}$. En nuestro país, A. M. Suárez ha llevado a cabo también un acercamiento a César en clave historiográfica -siguiendo, en buena medida, el esquema de Yavetz- en un par de trabajos ${ }^{27}$, pero al igual que el historiador israelí de origen rumano, la historiadora española considera fundamentalmente solo el "early Syme"28.

\footnotetext{
${ }^{21}$ SYME, 1960: 323-327; 1964: 134; 1980: 430 y 1986: 18, 18 n. 31; GAGO, en prensa.

${ }^{22}$ SYME, 1971: 40-42 y 1985: 12-14.

${ }^{23}$ SYME, 1971: 41 y 1986: 3-24; WisemAn, 1998: 135-136, 138-139 y 150-151; PeLLING, 2015: 234; GRIFFin, 2005; GAGO, en prensa.

${ }^{24}$ BOWERSOCK, 1980: 8.

${ }^{25}$ GAGO, en prensa.

${ }^{26}$ YAVETZ, 1971: 196-198 y 1983: 30-33.

27 SUÁREZ, 1997: 250 y 2004: 192-193.

${ }^{28}$ Escribimos "fundamentalmente" porque, en rigor, Suárez cita a pie de página un único trabajo de la etapa tardía de Syme (SUÁREZ, 2004: 192, n. 63; cfr. SYME, 1985: 12-14). Sin embargo, lo hace para justificar un párrafo en el que está abordando la aversión de Syme hacia la biografía, algo sobre lo que el historiador neozelandés venía hablando desde la década de los 30, y el cuadro que traza Syme de César como una figura trágica (esto, sí, característico del "late Syme"), aunque únicamente en un par de líneas y de una manera algo pobre y superficial.
} 


\section{LA CUESTIÓN DE LA PATERNIDAD DE M. BRUTO POR PARTE DE CÉSAR EN LA OBRA DE SYME, SUS ANTECEDENTES Y SU RECEPCIÓN}

Como someramente hemos adelantado, M. Bruto no resultaría ser hijo de César, en opinión del profesor neozelandés. Esta, a juicio de Syme, falsa atribución responde, de un lado, a la relación sentimental que mantuvieron César y Servilia y, de otro, al atractivo que el supuesto vínculo paternofilial César-Bruto ha tenido para dramaturgos y literatos en general e incluso psicólogos de tiempos ulteriores: "As a son of Julius Caesar, Marcus Brutus could not fail to appeal to men of letters in the later time, and to adepts of psychology, each encouraging the other to the detriment of sober truth" ${ }^{\prime 29}$. Por todo ello, el profesor oxoniense comienza explicando que es cierto que en la Vida de Bruto se registra la preocupación por parte de César durante la batalla de Farsalia por que M. Bruto no pereciera, ya que el estadista romano tenía cierta sospecha de que este fuera su hijo debido a su aventura con Servilia ${ }^{30}$. Sin embargo -añade- no encontramos ninguna mención a esa posibilidad ni en la Vida de Catón ni en la Vida de César, biografía esta última en la que, de hecho, se alude en dos ocasiones a la consideración de César hacia M. Bruto tras la batalla de Farsalia $^{31}$. La cuestión está relacionada, según Syme siguiendo el, a la sazón, reciente estudio de Chr. Pelling ${ }^{32}$, reputado especialista en Plutarco, con los métodos del biógrafo de Queronea así como con el orden en el que compuso esas biografías sobre romanos que cubren la última época de la República. Adicionalmente, nuestro autor achaca el hecho de que únicamente aparezca la señalada imputación de paternidad en la Vida de Bruto a las fuentes usadas en común por Plutarco y otros autores, y particularmente a la estrecha interrelación entre el de Queronea y Apiano. El historiador de Alejandría, al relatar las diferentes posibles razones de M. Bruto para unirse a la conjura, sí contempla como una de ellas la vergüenza debido a la posible paternidad por parte de César ${ }^{33}$. En cambio, Syme remacha lo diferente de las versiones tanto de Suetonio como de Dión Casio, quienes, a pesar de hacer-

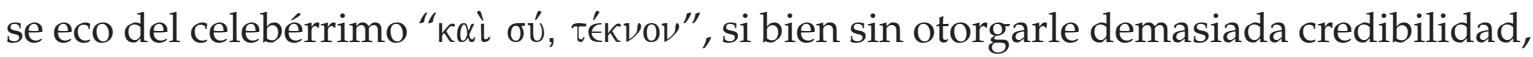
no se prodigan en mayores comentarios al respecto ${ }^{34}$.

Pero además, Syme esgrime otro argumento que, a su juicio, coadyuvaría a descartar la paternidad de M. Bruto por parte de César, a saber, la cronología: "Chronology is against Caesar's paternity" ${ }^{35}$. La datación del nacimiento de César había hecho correr, ya desde mediados del s. XIX, cuantiosos ríos de tinta. La polé-

\footnotetext{
29 SYME, 1960: 326; 1980: 436 y 1986: 18.

${ }^{30}$ Plut., Brut., 5; SyMe, 1939: 35, n. 1: "The liason was notorius [...] and gave rise to the vulgar and untenable opinión that Brutus was Caesar's son", había comentado Syme brevemente en su The Roman Revolution.

31 Plut., Caes., 46 y 62.

32 Pelling, 1979.

${ }_{33}$ ApP., BC, 2, 112.

${ }^{34}$ Suet., Iul., 82, 2; Dio. Cass., 44, 19, 5; SYME, 1960: 326 y 1980: 425-426.

${ }^{35}$ SYME, 1960: 326.
} 
mica fue abierta por W. Drumann, quien, ya en 1837, estableció la fecha del 13 de julio del 100 a.C. ${ }^{36}$ Esta opinión fue contestada pocas décadas después por Th. Mommsen con su celebérrima Römische Geschichte, donde defendió, basándose en las leges annales, la fecha del 12 de julio del 102 a.C. ${ }^{37}$ Su tesis fue aceptada por M. le Compte de Salis ${ }^{38}$, aunque notoriamente cuestionada por C. Nipperdey y por A. W. Zumpt, quienes apostaron por rebajar la fecha al año 100 a.C., y Zumpt, concretamente, además, prefirió decantarse por el día 13 basándose en el testimonio de Dión Casio ${ }^{39}$. Estos dos investigadores reivindicaron, en contra de Mommsen, el testimonio de ciertos autores antiguos, pero el erudito germano replicó a Nipperdey en su Römisches Staatsrecht que, si bien no tenía ningún problema en aceptar la posibilidad de que se eximiese a César de alguna de las obligaciones impuestas por las leges annales, ciertos pasajes de Suetonio no podían considerarse de forma razonable como base para el establecimiento de la cronología y que seguía opinando, por tanto, que la fecha del 12 de julio del 102 a.C. se le antojaba la solución más sencilla ${ }^{40}$. Esta reafirmación sin duda debió influenciar a muchos estudiosos como, por ejemplo, W. Warde Fowler, quien apostaría por la autoridad de Mommsen ${ }^{41}$. Iniciado el siglo XX, P. Groebe, corrigiendo y reeditando la obra de Drumann entre 1899 y 1908, y probablemente convencido por el estudio de Zumpt, mantuvo la fecha original del 13 de julio del 100 a.C. ${ }^{42}$ G. Ferrero y M. E. Deutsch, por su parte, propugnaron, de acuerdo con Nipperdey y Zumpt, y en contra de Mommsen, la fecha del 100 a.C. ${ }^{43}$; Deutsch, concretamente, a fin de explicar cómo César había alcanzado el consulado antes de lo establecido por ley, conjeturó que se le habría otorgado alguna exención no registrada entre su cuestura y su edilato ${ }^{44}$. Sin embargo, poco después T. R. E. Holmes abogó de nuevo por la propuesta mommseniana, es decir, el año 102 a.C., si bien trasladando el día 12 de julio al 13 del mismo mes, en un importante trabajo que después reproduciría en su celebérrima obra The Roman Republic and the Founder of the Empire ${ }^{45}$. De nuevo Groebe, en una de sus colaboraciones en la Pauly-Wissowa, cambió de criterio respecto al día y volvió a situar la fecha del nacimiento de César en el 12 de julio del 100 a.C., E. Meyer, en su celebérrima Caesars Monarchie und das Prinzipat des Pompeius, da otra vuelta de tuerca decantándose por la tesis de Mommsen, y M. Gelzer, por su parte, suscribe la opinión de Groebe aunque prefiriendo el día 13 al 12 ${ }^{46}$. El criterio gelzeriano sería suscrito por A. Piganiol y M. Cary,

\footnotetext{
36 DRUMANN, 1837, II: 129.

37 MOMMSEN, 1856, III: 15.

38 SALIS, 1866: 17-22.

39 Dio. Cass., 47, 18, 6; Nipperdey, 1865: 3 y ss. y 1870: esp. 3-4, 37 y 53-62; ZuMPT, 1874: 10-23.

${ }^{40}$ Mommsen, 1887, I' 570 y 570, n. 1.

${ }^{41}$ WARDE FOWLER, 1931: 12, n. 1.

${ }^{42}$ DrumanN-Groebe, 1906, III': 126.

${ }^{43}$ Ferrero, 1906, I: 238, n. 3; DeUtSCH, 1914: 17-28.

44 DeUTSCH, 1914: 23 y ss.

${ }^{45}$ HOLMES, 1917 y 1923, I: 221 y 436-442.

${ }^{46}$ Groebe, 1918: esp. 187; Meyer, 1919: 59, n. 2; Gelzer, 1921: 9. Meyer no cambiaría de opinión en su tercera edición no obstante el, a la sazón, reciente criterio de Gelzer (MEYER, 1922: 59, n. 2).
} 
quien lo defendería en su colaboración en la Cambridge Ancient History ${ }^{47}$. Sin embargo, poco después un investigador propondría una fecha hasta el momento inusitada: J. Carcopino, en dos importantes trabajos centrados exclusivamente en la cuestión del nacimiento de César y en su Points de vue sur l'impérialisme romain defiende basándose, como Mommsen, en las leges annales, el 13 de julio del 101 a.C. ${ }^{48}$ También se dio algún ingenioso intento de pretender establecer la edad de César fechando su matrimonio con Cornelia, la hija de Cinna ${ }^{49}$, pero más bien con poca repercusión. L. R. Taylor, investigando la fase más temprana del cursus honorum de César, apuntaló la explicación de Deutsch al documentar otros casos de carreras políticas irregulares que se habían beneficiado de exenciones en la República ${ }^{50}$. Ya en la década de los cincuenta, V. d'Antò manifestó su escepticismo respecto a la tesis de Carcopino y documentó la vaguedad de Suetonio con los números, especialmente, aunque no exclusivamente, en las Vidas imperiales. Aunque, a su juicio, parte de los errores radicaría en los copistas, otra buena parte lo haría en el defectuoso empleo de los números (redondeos a número mayor, mal uso de los cardinales) o de las fuentes por parte del propio ab epistulis de Adriano ${ }^{51}$. Otros investigadores, recuperando, de alguna manera, la conjetura que hiciera Deutsch a propósito de una exención entre la cuestura y el edilato de César, arrojaron otras hipótesis. Así, H. E. R. White especuló que la mencionada dispensa pudo hacerse con motivo de haber ganado la corona ciuica en el 80 a.C. ${ }^{52}$, y Badian, por su parte, propugnó que esta exoneración fue un privilegio otorgado a los patricios intentando compensar, de alguna manera, su exclusión tanto del tribunado como del edilato de la plebe, y apostó por el 100 a.C. ${ }^{53}$

De esta suerte se hallaba el panorama historiográfico en relación a la datación del nacimiento de César cuando Syme comienza a investigar su figura ${ }^{54}$, e incluso algo después. Su primera mención acerca de esta cuestión la hizo al reseñar la tercera edición de la icónica biografía de Gelzer sobre César ${ }^{55}$, donde, a despecho de no tomar él ningún partido en tan controvertida discusión, destaca la firmeza del autor

\footnotetext{
47 Piganiol, 1927: 389; CARY, 1932: 487.

${ }^{48}$ CARCopino, 1933; 1934a, 92, n. 1 y 1934b.

${ }^{49}$ SuET., Iul., 1; De SANCTIS, 1934; LAST, 1944.

${ }^{50}$ TAYLOR, 1941: 113-132.

${ }^{51}$ D'ANTOे, 1957.

${ }^{52}$ WHITE, 1950: 35 y ss.; cfr. SUET., Iul., 2.

${ }^{53}$ BADIAN, 1959.

${ }^{54}$ SYME, 1936. En rigor, Syme ya había consagrado un estudio a César escrito en 1932 o 1933, concretamente acerca de los planes del estadista romano respecto de Partia y Dacia, aunque no sería publicado hasta que A. Birley lo editara: SYME, 1999. E incluso, si bien fuera de su producción académica, podríamos también retrotraernos a una carta, sin fecha, proveniente del Archivo de Syme pero datada con seguridad hacia finales de la década de 1910, que un, a la sazón, jovencísimo Syme envió con motivo de la publicación de un artículo a un periódico local haciéndole notar flagrantes errores en ciertos aspectos de historia romana. Uno de ellos era especialmente craso, ya que confundía a Julio César con Augusto (BOWERsock, 1994: 541).

${ }^{55}$ SYME, 1944.
} 
alemán al decidirse por el año 100: "Gelzer decides for 100, firm against the authority of Mommsen and the blandishments of Carcopino" ${ }^{\prime 56}$. Una endécada después, también al reseñar, aunque esta vez, el segundo volumen del MRR, de T. R. S. Broughton, Syme parece adherirse a la tradición del 100 a.C., aunque admite que queda abierta la cuestión de cómo César accedió al consulado dos años antes de la edad establecida por las leges annales ${ }^{57}$. A pesar de su relativo silencio respecto a esta cuestión, y volviendo al periodo que principalmente nos ocupa, Syme -quizá influido por el reciente trabajo de su discípulo Badian- se alineará finalmente con Gelzer et al. frente a Carcopino: "[...] for Caesar, the best evidence indicates that he was born in 100"58; de ahí que, por tanto, a su juicio no pudiera ser padre de M. Bruto.

Otro importante argumento en contra de la paternidad de M. Bruto por parte de César que apuntalaría la tesis de Syme sería otra cronología, esta vez la del propio M. Bruto. Su establecimiento revestía una dificultad clamorosa debido a las múltiples contradicciones de las fuentes antiguas. La incoherencia principal surge entre el testimonio de Cicerón, que emplaza el nacimiento de M. Bruto entre el 86 a.C. y el 84 a.C. ${ }^{59}$, y el de Veleyo, que recoge que M. Bruto nació entre el 80 a.C. y el 78 a.C. $(2,72,1)^{60}$. Adicionalmente, otros testimonios, si bien más ambiguos, coadyuvan a enmarañar más la cuestión. Así, al decir de Livio, cuando M. Bruto se suicida tras Filipos "Tenía cerca de cuarenta años" ${ }^{\text {"61. }}$ Plutarco sostiene que en el 58 a.C. M. Bruto era "todavía joven" ${ }^{2}$, y Apiano, por su parte, lo califica también de "joven" incluso en el 44 a.C. ${ }^{63}$ En fin, una fuente tan tardía como Aurelio Víctor asegura que en el 53 a.C. M. Bruto rehusó servir bajo las órdenes de César en la Galia y en su lugar acompañó a su suegro Apio Claudio a Cilicia como cuestor, lo que, según las leges annales, implicaría que M. Bruto habría nacido en el 83 a.C. ${ }^{64}$

Desde un primer momento se desdeñaron los testimonios tanto de Veleyo como de Livio: en el s. XIX Drumann rechazó sus versiones y se decantó por la de Cicerón ${ }^{65}$. Algunas décadas después, Nipperdey intentó conciliar las dos fuentes

${ }^{56}$ Ibíd., 101.

${ }^{57}$ SYME, 1955: 131.

${ }^{58}$ SYME, 1960: 326; cfr. 1980: 422.

${ }^{59}$ CIC., Brut., 324; cfr. 229.

${ }^{60}$ Vell., 2, 72, 1. La mayoría de editores ha adoptado esta tradición del manuscrito (SHIPLEY, 1924: 202; HellgouARC'H, 1982: 80; SÁNCHEZ, 2001: 181), aunque tanto J. Hellegouarc'h, quien conjetura sobre un posible error del propio Veleyo o de un copista (1982: 218), como $\mathrm{M}^{\mathrm{a}}$ Asunción Sánchez, que se limita a constatar a pie de página que M. Bruto nació en el 85 a.C., no aceptan el año 78 a.C. como fecha de nacimiento de M. Bruto. A. Ruiz, en su reciente edición de la obra de Veleyo, adopta otra tradición decantándose por "XXXXII annum" (RUIZ, 2014: 270).

${ }^{61}$ LIv., Perioch., 124, 4; trad. J. A. Villar. Existe una laguna justo detrás del guarismo, aunque "en la que presumiblemente se mencionarían otros participantes" (VILLAR, 1995: 186, n. 521).

${ }_{62}$ Plut., Brut., 3, 1; Cat. min., 5-6; trads. J. P. Sánchez y M. González.

${ }_{63}$ App., BC, 2, 99; trad. A. Sancho.

${ }^{64}$ Aur. Vict., De vir. Ill., 82, 3.

${ }^{65}$ Drumann, 1838, IV: 18 y 18 n. 33. 
más concretas y cercanas cronológicamente a $\mathrm{M}$. Bruto, al proponer una corrección del pasaje del Bruto para hacerlo coincidir con el de Veleyo: "[...] daß Cicero nicht decem, sondern sedecim geschrieben hat" ${ }^{\prime \prime 6}$. Abierta así la polémica, no pocos editores de Cicerón -por no decir prácticamente todos-, de acuerdo con Plutarco y con Apiano, han adoptado la corrección de Nipperdey ${ }^{67}$, y a la sazón varios especialistas pretendieron otorgar credibilidad al susodicho pasaje de Veleyo ${ }^{68}$, aunque fueron replicados por Groebe, quien concedió más verosimilitud al comentado pasaje de A. Víctor ${ }^{69}$, y por Gelzer, que adujo que E. T. Bynum y O. Seeck no aportaban una sola prueba convincente ${ }^{70}$. Münzer, por su parte, agregó al debate la evidencia de que las relaciones entre César y Servilia no se habrían dado hasta el 59 a.C. -relaciones que, según Gelzer ${ }^{71}$, explican la intervención de César, en cuanto que cónsul, en el caso del informante Vetio para exculpar a Servilio Cepio (es decir, a M. Bruto, quien, adoptado por su tío, llevaba su nombre a la sazón)-, lo que descartaría absolutamente la paternidad de M. Bruto por parte de César ${ }^{72}$. Décadas más tarde, la postura del prosopógrafo alemán sería abonada por otro distinguido investigador, aunque admitiendo que no se podía asegurar la fecha precisa del nacimiento de M. Bruto: "Il serait né, selon les uns en 85 avant J.-C.; selon d'autres, en 82 , ou bien en $78^{\prime \prime 73}$.

12 La opinión de Syme sobre la fecha de nacimiento de M. Bruto es que, en virtud de que este fue cuestor en el 54 a.C., su nacimiento no pudo ser posterior al 85 a.C., cuando César apenas contaba con 14, 15 o, en el mejor de los casos -según Carcopino-, 16 años. Syme nos confirma esta cronología con un, a su juicio, fiable pasaje ciceroniano que asegura que el futuro cesaricida nació en el 85 a.C. ${ }^{74}$ ¿Y por qué esta confianza en el arpinate por parte de Syme, considerando las escasas simpatías que le merece el gran orador? $?^{75}$. Según el investigador neozelandés, en aquel tiempo ningún senador podría desconocer este tipo de informaciones habida cuenta de la feroz competencia que existía con motivo de los honores públicos: “No se-

\footnotetext{
${ }^{66}$ NiPPERDEY, 1864: 291.

${ }^{67}$ Adoptan la corrección de Nipperday en $\S 324$ del Brutus A. S. Wilkins y J. Martha en todas sus respectivas ediciones del texto desde 1903 y 1923 (WILKINS, 1903: 94; MARTHA, 1923: 120), y F. Galli, quien, además, recalca en el comentario que M. Bruto habría nacido "tra il 79 ed il 78" (GALLI, 1981: 271). También por A. E. Douglas, aunque ya con ciertas reservas (DouglAs, 1966: 229-230), pero no así E. Malcovati, que confía en la auctoritas de Drumann-Groebe y de Gelzer (MALCovATI, 1960: 336 y 1970).

${ }^{68}$ BYNUM, 1907: 6 y ss.; SEECK, 1901 y 1907.

${ }^{69}$ Groebe, 1907: 314; Drumann-Groebe, 1908, IV²: 21 y 21 n. 10.

${ }^{70}$ Gelzer, 1918: 973-974.

${ }^{71}$ Ibíd., 975-976.

72 MÜNZER, 1923: 1817-1821; cfr., Att., 2, 24, 3.

${ }^{73}$ CARCOPINO, 1947, II: 122-128.

${ }^{74}$ Cic., Brut., 324, cfr. 229.

${ }^{75}$ Syme había consagrado a Cicerón un capítulo entero en The Roman Revolution: "X. The Senior Statesman" (SYME, 1939: 136-148), aunque, como apunta V. Alonso, con un tono ciertamente desfavorable (cfr. AlONSO, 1990: 52, n. 13).
} 
nator of the time would be liable to ignorance or inadvertence. Friends or enemies in competition were acutely aware of ages and stages in the cursus honorum". Por ello, el del arpinate se le antoja un testimonio mucho más verosímil que el de un autor que escribió setenta años después de la batalla de Filipos, y que el de otro después de cuyo testimonio existe una laguna ${ }^{76}$.

Ahora bien, que César no fuera el padre de M. Bruto no implica, como sostuvo Balsdon, que César adoleciera de infertilidad tras haber concebido a Julia' ${ }^{77}$, pues, a despecho de que Balsdon justifique su postura mediante opiniones de colegas médicos, estos testimonios, como matiza Syme, son "anonymous and not specific"78. Adicionalmente, la ubicación de la fecha de nacimiento de Julia en el año 75 a.C. -en tanto en cuanto estaba aún soltera en el 59 a.C.-, siguiendo a Gelzer ${ }^{79}$, -y no en el 83 a.C., como apuntó Münzer ${ }^{80}$, a quien sigue Balsdon- representa, para Syme, otro argumento en contra de la tesis de Balsdon ${ }^{81}$. Syme, no sin antes advertir de lo frustrante y arriesgado que puede resultar la investigación de los bastardos en la aristocracia, esgrime, además, otros tantos motivos que, en cualquier caso, podrían haber contribuido a que el nombre de un supuesto vástago de César no hubiese llegado hasta nosotros. Fenómenos como la progenie escasa o la mortandad infantil raramente eran registrados por los autores antiguos salvo que concerniesen al discurso biográfico. Por otro lado, el profesor neozelandés esgrime también la incidencia de las plagas y de las "unhealthy seasons". Por último, Syme subraya el factor del adulterio, práctica, a su juicio, muy documentada pero no así ninguna de sus consecuencias; y, relacionado con ello, remacha las conocidas aventuras de César con cuantiosas illustres feminae pero también con varias princesas a lo largo de su prolongada estadía por toda la cuenca mediterránea, idilios cuyos frutos resultan muy complicados de registrar: "Like Conquistadores in Mexico and Peru, Caesar and his officers enjoyed access to princesses in a frequentation through the long sojourn that leaves no other traces" ${ }^{\prime 82}$.

Retornando al debate acerca del establecimiento de la cronología del nacimiento de César, se puede considerar que, aunque con matices, tras las investigaciones realizadas por Syme, la cuestión se encuentra aún abierta, pues hallamos defensores tanto del 100 a.C. ${ }^{83}$, como del 101 a.C. ¡e incluso -como defendiera

\footnotetext{
${ }^{76}$ SYME, 1960: 326; 1980: 422, 422 n. 29 y 426 y 1986: 18.

77 BALSDON, 1958: 86-87 y ss. y 1960: 69.

78 SYME, 1980: 423.

79 Syme está citando la versión original de la obra de M. Gelzer, esto es, del año 1960, y nos proporciona tanto la página 19 como el año 75 a.C. para el nacimiento de Julia. Sin embargo, en la traducción al inglés a cargo de P. Needman, que es la que hemos manejado, Gelzer habla del año 76 a.C., dato que se encuentra en la p. 21 (GELZER, 1968: 21). En todo caso, opinamos que esta diferencia insignificante no altera el argumento de Syme.

80 MÜNZER, 1918: 894.

${ }^{81}$ SYME, 1986: 18.

${ }^{82}$ SYME, 1980: 423-425 y 435-436.

83 Suet., Iul., 88; PluT., Caes., 69; ApP., BC 2, 149; Vell., 2, 41, 2.
} 
Mommsen- del 102 a.C..$^{184}$, si bien el año 100 a.C. es el que mayor consenso genera. Por otro lado, las opiniones aún están divididas acerca de qué día nació exactamente el potentado romano, si el $12^{85} \mathrm{o}$ el 13 de julio ${ }^{86}$. Carcopino, inasequible ante las críticas, porfió en su Profils des conquérants, en su Les étapes de l'imperialisme romain y en la última reedición de su icónico Jules César antes de fallecer, en el 13 de julio del 101 a.C. ${ }^{87}$ En cualquier caso, la opinión que sugería el día 13 es la que ha calado hondo, pero conjugándose con la del año 100 a.C. ${ }^{88}$ M. Grant, que toma por buena la exégesis de Badian, opta por la fecha del 13 de julio del 100 a.C., en función del año del primer consulado de César (59 a.C.). Chr. Meier y A. Goldsworthy se refieren en su justificación a que César nació el tercer día antes de los idus de Quintilis, aludiendo así, aparentemente, al comentado pasaje de Macrobio (Sat., 1, $12,34)$, si bien el autor alemán se muestra más cauteloso porque, en tanto en cuanto Roma empleaba un calendario lunar a la sazón -argumenta-, a su juicio no es seguro que la fecha corresponda exactamente al 13 de julio en nuestro año solar. G. V. Sumner, por su parte, si bien no acabó de decidirse por una opción, admite que, de haber nacido César realmente en el 100 a.C., la exégesis de Badian le resultaría admisible. Y agrega que difícilmente se podrían emplear como evidencia para esta cuestión las monedas en las cuales figura tanto una cabeza de mujer como el numeral "LII" en su anverso y la palabra "CAESAR" en su reverso ${ }^{89}$. En virtud de los tesoros en los que se hallaron, M. H. Crawford las dató con una cronología en todo caso posterior al 48 a.C. ${ }^{90}$, lo que hace pensar a Sumner que, en el caso de que el numeral "LII" significase 52 años, ello aludiría más probablemente al intervalo de años entre las grandes victorias de Mario (102-101 a.C.) y la culminación de la conquista de la Galia por César en el año 50 a.C. ${ }^{11}$ Por último, Badian ha vuelto a defender la opción del 12 de julio del 100 a.C. reivindicando el señalado testimonio de Macrobio acerca de la ley aprobada por el cónsul M. Antonio (i. e. en el 44 a.C.) que cambiaba el nombre del mes Quintilis a Iulius "porque en el curso de este mes, el cuarto día antes de las idus de Quintilis, habia nacido Julio"${ }^{\prime 92}$. Badian recalca que el numeral está escrito al margen del manuscrito y que no existen variantes textua-

\footnotetext{
${ }_{84}$ "Cadoux accepts 102 as the year of birth and asks: «Does 'ante tempus' make it certain he did not serve two or more governors instead one, for some special reason? Must Vetus' governorship follow, and not precede, that of Pupius Piso? Must the levy in Cisalpine Gaul be in 68?»" (cit. en BROUGHTON, 1986: 105-106). Por cierto que al propio Broughton, en su último volumen del MRR, la fecha de nacimiento basada en la edad de César al morir (i.e. 100 a.C.) es la que se le antoja mejor atestiguada (BROUGHTON, 1986: 105).

${ }^{85}$ MACROB., Sat., 1, 12, 34.

${ }^{86}$ Dio. Cass., 47, 18, 6.

${ }^{87}$ CARCOPINO, 1961a: 241-286; 1961b: 120 y 1968: 3.

${ }^{88}$ Gelzer, 1968: 1, 208, n. 3; Oppermann, 2004: 29; Grant, 1969: 29-30; Meier, 1982: 70; GoldSWORTHY, 2007: 49; FREEMAN, 2009: 13.

${ }^{89}$ Cfr. SydenHAM, 1952: 167 y ss.

${ }^{90}$ Cfr. CRAWFORD, 1969: tabla XIV.

${ }^{91}$ SUMNER, 1973: 134-137.

${ }_{92}$ Trad. A. Navarro; "quod hoc mense a.d. quartum idus Quintiles Iulius procreatus sit" (cfr. WILLIS, 1970: 60).
} 
les. Pero además, el historiador de origen austríaco pone de manifiesto el que todas nuestras fuentes concuerdan con la fecha hasta Juan Lido, en el s. VI, con la sola excepción de Dión en el s. III d.C., quien proporciona el día 13 de julio debido a que el día fue oficialmente cambiado al 12 de julio mediante una ley de los triunviros, aunque no cita su fuente ${ }^{93}$.

También está cargado de razón el comentario de Syme, respecto al atractivo que el supuesto vínculo paternofilial César-Bruto ha tenido para estudiosos poste-

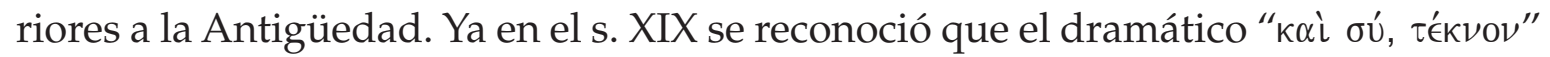
-sobre el que nos extenderemos más adelante- tenía un origen puramente legendario $^{94}$. Más recientemente se ha señalado que esas últimas palabras de César a M. Bruto, y por extensión toda su relación en vida, provocan que el destino de los dos protagonistas adquiera así una nueva dimensión trágica del mejor efecto en el plano literario, introduciéndonos, de esta forma, en un universo dramático cuyo tono sublime contribuye todavía más al engrandecimiento de César frente a un asesino cuyos designios no son honorables y a quien se le avecina un destino próximo y funesto. En este sentido, Bruto habría sido conducido por la avidez de poder más que por el idealismo, y la anécdota en cuestión habría sido inventada post eventum dentro de la propaganda anti-tiranicida; de ahí que, en cualquier caso, la elección de la cita podría haberse inspirado en consideraciones, amén de literarias, políticas $^{95}$. M. Wyke y otros autores, por su parte, subrayan el hecho de que Dante, en su Divina comedia, ubique a M. Bruto en lo más profundo de la sima infernal, en la boca de Lucifer, junto a Judas, sugiere, según la autora, un vínculo entre los traidores de César y los de Cristo ${ }^{96}$.

En otros trabajos, enfocándose más concretamente en la alusión que hacía Syme respecto a las implicaciones en el campo de la psicología que ha alimentado la supuesta relación padre-hijo entre César y M. Bruto, se han llevado a cabo algunas observaciones en clave freudiana. Así, T. W. Africa recuesta, de alguna manera, a M. Bruto sobre el diván y, en un acercamiento psicohistórico, concluye que se puede identificar al cesaricida como una personalidad anal: autodisciplinado, parsimonioso, obstinado, impulsivo, propenso a autoculpabilizarse y agresivo ${ }^{97}$.

${ }_{93}$ BADIAN, 2009: 16. E. Cary, en su edición crítica, interpreta este pasaje de Dión en el sentido de que, como cambiar el cumpleaños de César al día 12 hubiese significado lo mismo que mantenerlo en el 13 -pues aunque en el 208 a.C. los Ludi Apolinares se establecieron en el 13 de julio, para el 42 a.C. se celebraban entre el 6 y el 13 de este mes-, Dión, al hablar del día anterior, se está refiriendo en realidad al día 5 de julio (CARY, 1917: 145, n. 1).

${ }^{94}$ DRUMANN, 1837, III: 730-731.

${ }_{95}$ ARNAUD, 1998: 68 y 71.

${ }^{96}$ WYKE, 2006: 178; MCLAUGHLIN, 2009: 336.

${ }^{97}$ AFRICA, 1978: 599-626. A su juicio, aunque su dinámica contribuye al éxito en muchos campos, la personalidad anal es una armadura dentro de la cual se encuentra un niño encapsulado con feroces emociones. En las crisis emocionales, particularmente en las de rechazo u oposición, los sentimientos reprimidos pueden estallar desembocando en actos de furia cada vez más intensos y peligrosos cuando se racionalizan en términos aceptables para la mente consciente, como el tiranicidio. 
N. Royle, por su parte, ha abordado el episodio de la aparición del "fantasma de César" o del "espíritu malo" en la tienda de campaña de M. Bruto que acaece en el Julius Caesar shakesperiano ${ }^{98}$. A su juicio, el pasaje pondría de manifiesto una sensación de culpa por parte de M. Bruto, el regreso de lo reprimido, el síntoma insistente de un crimen en última instancia irreprimible -"Thanks to Shakespeare, we are all haunted by Caesar's ghost" ${ }^{\prime \prime 9}$. De alguna manera, la autoridad del líder muerto sigue viva y, como S. Freud señala en su Totem y Taboo, ese líder masculino o figura paterna que ha sido asesinado por "the primal horde" es en ciertos aspectos más poderoso muerto que cuando se hallaba con vida. M. Bruto resultaría ser uno de esos personajes de los que, según Royle, Freud habla como "wrecked by success": se las arregla para llevar a cabo lo que aparentemente se ve obligado a hacer (i.e. matar a César), pero enseguida cae en la cuenta de que no puede lidiar con las consecuencias de su éxito. Además, el cesaricida parecería estar notablemente afectado por la fuerza insidiosa de lo que también Freud denomina, al decir de Royle, como "deferred obedicence", esto es, el paradójico proceso por el cual alguien pretende rechazar, evadir o revocar la influencia o autoridad de otro (especialmente una figura paternal) pero termina amoldándose a este otro, actuando, en este caso, de manera suicida ${ }^{100}$.

En la dramática versión de Plutarco en la que M. Bruto apuñala a César en la ingle ${ }^{101}$, el cesaricida actuaría así como una suerte de Cronos, en tanto en cuanto es

Así pues, para Africa, la prima facie desconcertante elección de bando por parte de M. Bruto en el 49 a.C. resulta, sin embargo, obvia en términos freudianos: a fin de cuentas, César era la pareja sexual de Servilia y, por tanto e inconscientemente, el rival de M. Bruto. Asimismo, Africa advierte una similitud edípica entre la situación de M. Bruto y la de L. Bruto, quien también decidió actuar cuando una mujer virtuosa fue deshonrada por el tirano: "Whoever put up the placards knew M. Brutus very well", asegura Africa (cfr. PLUT., Brut., 9-5). Y se cuestiona Africa respecto al célebre "espíritu malo" que se apareció a M. Bruto en su tienda: ¿Acaso M. Bruto, consciente de su culpa, que había roto un juramento y asesinado a su "padre", se veía a sí mismo, a su naturaleza malvada, en la figura amenazante? ¿O fue la horrible aparición del padre asesinado, conjurado por la culpa del parricidio? Tanto si se veía a sí mismo como si veía a César con una apariencia monstruosa, los sentimientos de culpa de M. Bruto le produjeron una alucinación en Sardis.

${ }_{98}$ 4.4.273-87. Shakespeare bebe aquí de los pasajes Caes., 69, 6-14 y Brut., 36, 6-7 de Plutarco, quien registra esta aparición del mal daímon de M. Bruto o malus genius. Según J. P. Sánchez y M. González, representa un episodio singular y en común con Dión, quien también sufre la aparición de una Erinia trágica o divinidad vengadora (Dio, 55, 2) -Diosas de la venganza, bien conocidas en la escena trágica por la obra Euménides de Esquilo. Plutarco no carga demasiado las culpas sobre M. Bruto al escribir su biografía, pero cuando lleva a cabo la de César sí escribe que el tiranicidio no fue bien considerado por los dioses, de ahí el espectro que se le apareció al asesino. Adicionalmente, los susodichos editores conjeturan que la imagen de Antonio desplegando las ropas ensangrentadas de César ante la muchedumbre enfurecida podría ser el desencadenante de una tragedia enfocada en esa venganza por cuya ejecución velaría la Erinia (SÁNCHEZ y GONZÁLEZ, 2009: 251, 253, 327, n. 142, 373, n. 117).

99 GRIFFIN, 2009: 391.

${ }^{100}$ ROYLE, 2006: 210-211.

${ }^{101}$ Plut., Caes., 66. 
el hijo que castra y depone a su tiránico padre atacándolo en la fuente prístina de la paternidad solo para convertirse a sí mismo en la víctima de la violenta lucha por el poder ${ }^{102}$. Este relato de Plutarco ha sido interpretado por Pelling como un intento de vincular el pasaje, de forma desagradable, con la cuestión de la paternidad de César ${ }^{103}$. Sin embargo, a pesar de que alguna reciente biografía ha tomado por bueno el pasaje sin un mínimo comentario ${ }^{104}$, se ha apostillado que el relato suena demasiado bien como para ser cierto, habida cuenta del papel que el biógrafo está atribuyendo justamente al supuesto hijo natural de César ${ }^{105}$.

De todos modos, y centrándonos estrictamente en la investigación historiográfica, los trabajos posteriores a Syme han tendido, como él, a rechazar la posible paternidad de M. Bruto por parte de César. Ya a finales de los años sesenta, se defendió la postura de que dicha posibilidad era una invención de corte sentimental notoriamente falsa ${ }^{106}$. También diversos editores, sobre todo de la Vida de Bruto ${ }^{107}$ pero también de Veleyo y de Suetonio ${ }^{108}$, han tendido a descartar la posible paternidad valiéndose, sobre todo, de argumentos cronológicos o metodológicos de la obra de Plutarco. Sin embargo, también los historiadores, igual que los filólogos, han hecho hincapié en el factor cronológico ${ }^{109} \mathrm{y}$ en las pocas y pobres pruebas que, a fin de cuentas, sustentan el rumor de la paternidad ${ }^{110}$ : un costoso regalo de César

${ }^{102}$ ZIOGAS, 2016: 136.

103 Pelling, 2011: 482.

${ }^{104}$ GOLDSWORTHY, 2007: 652.

105 STRAUSS, 2015: 167-168.

106 OppermanN, 2004: 199; cfr. MAcMullen, 1966: 2; contra RAMBAUd, 1974: 117.

107 Así, por ejemplo, R. Flacelière y E. Chambry se han fiado del testimonio del Arpinate sobre el de Veleyo et al. "car Cicéron était bien placé pour savour quand son ami était né" (FLACELIÈRE y Chambry, 1978: 77). En nuestro país, J. P. Sánchez y M. González han matizado que el favor que M. Bruto recibe por parte de César destaca, no tanto por motivo de paternidad alguno, cuanto como un elemento más en común entre la biografía Bruto y la de Dión, quien también disfrutó del amparo del tirano de Siracusa (SÁNCHEZ y GONZÁLEZ, 2009: 339, n. 26). En este sentido se expresa también el recientemente desaparecido J. L. Moles, quien matiza que a despecho de que Plutarco sea escéptico respecto de la tradición romántica que vincula a César, Servilia y M. Bruto, registra ciertos pasajes que aluden a ella (Brut., 5) porque crea una impresión general de cercanía entre M. Bruto y César. Pero ciertamente no concede importancia a la tradición de que M. Bruto era el hijo de César, ni tampoco se deja llevar por lo que el profesor irlandés entiende como vulgares especulaciones sub-freudianas de que M. Bruto estaba avergonzado del adulterio de Servilia -a diferencia, dice, de Apiano (BC, 2, 112, 469) y de muchos otros autores modernos como M. Radin, R. MacMullen y el propio Syme (Moles, 2017: 93; cfr. SYME, 1939: 58 y 1980: 436). Por cierto, en esta misma página de The Roman Revolution, Syme comenta algo sobre M. Bruto ostensiblemente relacionado con su bochorno por el adulterio de su madre mediante lo que, según V. Alonso, el autor oxoniense cala a M. Bruto hasta el fondo: "His was not a simple personality - but passionate, intense and repressed" (cfr. AlONSO, 1990: 58).

${ }^{108}$ R. Ma Agudo y Ma A. Sánchez, que editan a Suetonio y a Veleyo respectivamente, aceptan solo la fecha del 85 a.C. (AGUdo, 1992: 161, n. 348; MANZANO, 2001: 181, n. 500), y Agudo deduce de ello lo improbable de la paternidad.

109 Dubuisson, 1980: 884; GOlDSWORTHY, 2007: 117; STRAUSS, 2015: 47.

110 PAterson, 2009: 137-138. 
a Servilia ${ }^{111}$, una ocurrencia salaz de Cicerón ${ }^{112}$, un misterioso intercambio entre César y Catón en el debate sobre el destino de los catilinarios el 5 de diciembre del 63 a.C. ${ }^{113}$, y la voluntad de César de salvar a M. Bruto en Farsalia ${ }^{114}$. Gelzer, en relación a este último rumor, apunta que, no obstante César estuviese particularmente satisfecho a nivel personal por ser Bruto hijo de Servilia, la adhesión de este a su bando le resultaba mucho más valiosa en clave política, sobre todo por la relación, tanto de parentesco pero sobre todo filosófico-política, que el futuro cesaricida compartía con Catón ${ }^{115}$. B. Strauss, por su parte, señala que César no era un sentimental, y que si la narración es cierta se trataría de un movimiento en clave política en deferencia a Servilia e independiente de la paternidad, o si no, siendo conocedor de los rumores de la paternidad, aunque fuesen falsos, no desearía dar pie a la más mínima sospecha de que había eliminado a su propio hijo ${ }^{116}$. Por último, Moles ha señalado en un pormenorizado comentario de la Vida de Bruto de Plutarco que la teoría de la paternidad de César es claramente una ficción romántica, pese a los argumentos presentados por Balsdon y Münzer, quienes solo la descartaban por motivos cronológicos ${ }^{117}$. La única excepción entre los trabajos más recientes ha sido la propuesta, ingeniosa pero poco convincente, de D. Porte. La historiadora francesa subraya el hecho de que Veleyo, como Cicerón, estaría "bien placé lui aussi", se habría codeado con los familiares de M. Bruto y recuerda -en contra de Badian $^{118}$ - el hecho de que es conocido por su puntillismo en materia de fechas y edades, todo lo cual, sumado a los testimonios de Plutarco y Apiano, le lleva a concluir que M. Bruto habría nacido en octubre del 78 y que era, en efecto, hijo natu-

111 Suet., Iul., 50, 2; MACrOB., Sat., 2.2.5.

112 Cic., Att., 2, 24, 3.

113 Plut., Cat., 5, 3-4.

114 Plut., Brut., 5, 1; ApP., BC, 2, 112. Otros estudiosos, como Badian y Sumner, si bien no se refieren directamente al tema de la paternidad César-Bruto, indirectamente la descartan al fiarse del criterio de Malcovati (supra, n. 62) en su edición (BADIAN, 1967: 229; SUMNER, 1971: 365-366 y 1973 : 154). Badian, cuyo comentario es algo más prolijo que el de Sumner, esgrime como argumentos la desconfianza qu le merece Veleyo y la vaguedad que caracteriza a todas las Vidas de Plutarco.

115 GELZER, 1968: 243.

116 STRAUSS, 2015: 48.

117 Moles, 2017: 92-93. A su juicio, el rumor convendría tanto a los partidarios de M. Bruto (al probar así su increíble desinterés) como a sus detractores (añadiendo el crimen del parricidio al de la flagrante ingratitud), y armonizaría convenientemente con la tradición familiar de los Iunii Bruti (la ejecución de los hijos del primer cónsul por él mismo). Pero además, el profesor irlandés especula acerca de tres motivos específicos más para la invención de la paternidad: la interpreta-

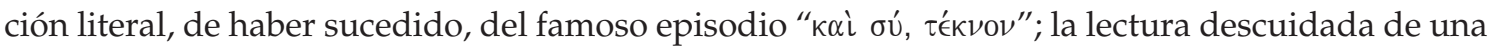
carta de M. Bruto en el sentido de que mató a su padre (Cic., Ad Brut., 1, 16); y la malinterpretación de una referencia a los "maiores nostri" de un pasaje de este mismo epistolario (Ad Brut., 1, 17): la leyenda sobre que L. Junio Bruto, uno de los "maiores" de M. Bruto, era hijo de Tarquino el Soberbio podría haberse difundido entonces (la genealogía de los Tarquinos es confusa, y según Diodoro $(10,22)$ y Livio $(1,56,7)$ L. Junio Bruto era su sobrino).

${ }^{118}$ Cuando el historiador de origen austríaco defendía precisamente que "Velleius' dates are notoriously unreliable" (BADIAN, 1967: 229). 
ral de César ${ }^{119}$; en nuestro país, esta tesis ha sido defendida por uno de los pocos autores de una biografía de César en español, J. Cabrero, quien comenta que es muy probable que así fuera ${ }^{120}$.

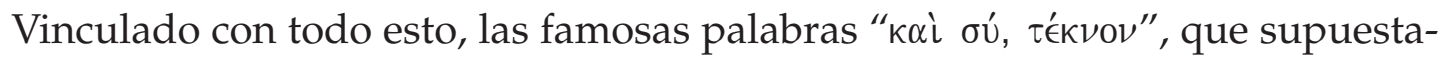
mente César dirigió a M. Bruto, y que a Syme, basándose en el propio desdén de los autores antiguos, inspiraban poca confianza, han generado un prolongado y encendido debate erudito. Como hemos comentado sucintamente líneas arriba, Drumann negó la autenticidad del pasaje -“die Erzahlung [...] ist zugunsten der Sage ersonnen, welche ihn den Vater des Brutus nennt"- ${ }^{121}$, y, ya en los ss. XX y XXI, numerosos investigadores, tanto historiadores como editores, expresaron serias dudas al respecto: interpretando literalmente las palabras de César -de padre a hijo- ${ }^{122}$, siguiendo la tesis de Drumann ${ }^{123}$ o por no hallarse el pasaje en todas las fuentes sumado al hecho de que las relaciones entre César y Servilia comenzaron después del nacimiento de M. Bruto ${ }^{124}$. Puede que, como también se ha apuntado, la función de la anécdota dentro de la arquitectura de la historia sea recordarle al lector por última vez la infamia Caesaris ${ }^{125}$. Solo se ha esgrimido un argumento en favor de la autenticidad: en tanto en cuanto la frase se pronunciaría en griego, representaría un ejemplo de la profundidad de este idioma, en términos de bilingüismo, en la conversación ordinaria de la élite romana ${ }^{126}$, y no la voluntad del dictador de no ser entendido por todos, como sostenían algunos eximios plutarquistas ${ }^{127}$. Por último, recientemente B. Strauss ha abogado, como la tendencia mayoritaria, por la inautenticidad esgrimiendo que probablemente César no dijese nada relacionado con el célebre epitafio oral, y que el relato se inventaría a posteriori, al desencadenarse la controversia sobre el papel de M. Bruto aquel día; así, especula que "Resulta más sencillo imaginar a César empleando sus últimas palabras para mostrar con un grito indignado la villanía de Casca". Pero ni el propio Strauss, por lo demás aséptico, escéptico y poco dado a patetismos, puede evitar caer en esa fascinación dramática del vínculo César-Servilia-Bruto que señalaba Syme ${ }^{128}$.

${ }_{119}$ PORTE, 1994.

${ }^{120}$ CABRERO, 2004: 261-262.

${ }^{121}$ DrumanN, 1837, III: 730-731; DrumanN-Groebe, 1906, III²: 656.

122 Butler y CARY, 1927: 149; AILOUd, 1931: 58, n. 1.

${ }^{123}$ WALTER, 1938: 130, n. 3.

${ }^{124}$ LINTOTT, 2009: 79.

${ }^{125}$ Gugel, 1970.

${ }^{126}$ DubuisSON, 1980; MARTIN, 1988: 21-22. P. Freeman también aboga por la autenticidad, aunque, siguiendo la misma tónica del resto de su obra, sin ninguna reflexión mínimamente crítica (FrEEMAN, 2009: 368).

${ }^{127}$ FlaCelière y ChAmbry, 1975: 138 y 138 n. 3.

${ }^{128}$ Admite que nunca se conocerá la manera en que César respondió a M. Bruto, si es que lo hizo. Añade que Décimo, que le había engañado ese mismo día, le era más próximo, y se puede deducir que su traición le dolió más que la de Marco, "Pero en la relación entre ambos había una tercera figura: Servilia. Su conexión con César era un asunto sentimental, y el corazón tiene sus razones. Así pues, tal vez la traición de M. Bruto se le clavase más hondamente" (STRAUSS, 2015: 168-169). 
En cualquier caso, la historiografía, probablemente consciente de lo prácticamente imposible que resulta determinar si tal episodio sucedió o no, se ha centrado en determinar el posible significado de las palabras del prohombre romano más que

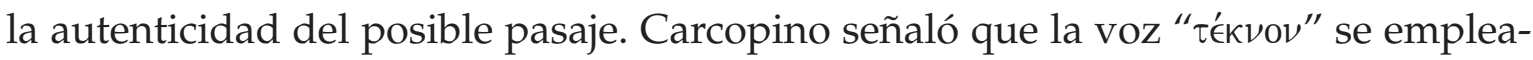
ba corriente como un término de afecto hacia alguien más joven -algo así como "mi pequeño" ("mon petit", en términos del autor francés)- y, por tanto, no existían motivos para deducir de la exclamación de César el menor indicio de que M. Bruto fuese su hijo ${ }^{129}$. La propuesta del normalien fue seguida por varios estudiosos ${ }^{130}$, aunque también se dieron múltiples explicaciones alternativas. Una posibilidad reside en que un agonizante César estuviese maldiciendo a $\mathrm{M}$. Bruto mediante una fórmula apotropaica, profiláctica o retributiva: “QQue te ocurra lo mismo!”, expresión habitual en las tablillas de maldiciones relacionadas con lo que J. Russell explica como "the Evil Eye or Envy", y que el profesor norteamericano pretende demostrar con una plétora de evidencias arqueológicas ${ }^{131}$. Russell fue criticado por F. Brenk, quien, mediante una estela honoraria dedicada a Nerón -con las misteriosas palabras KAI $\Sigma Y$ sobre la inscripción principal-, una digresión sobre material tanto literario como arqueológico acadio y sumerio, así como argumentando lo inusitado de fórmulas supersticiosas por parte de César, cuestiona interpretar las palabras postreras del dictador a través del "Evil eye or Envy"132. Otra interpretación sería la de los autores que se han tomado las palabras de forma literal ${ }^{133}$, por ejemplo M. Rambaud o D. Porte, quienes, en buena lógica con sus tesis de la paternidad efectiva por parte de César, exponen que el dictador estaría reconociendo a M. Bruto como hijo ${ }^{134}$; pue-

129 CARCOPINO, 1961a: 291-293 y 1968: 564, n. 4.

130 Etienne, 1973: 171; MARTin, 1988: 21; Dickey, 1996: 68-69; Picón, 1998: 225, n. 569; Moles, 2017: $92-$ 93. E. Dickey matiza que, a despecho de que el vocativo "teknon" es usado de forma mucho más regular que la alternativa de pai por los padres o aquellos en loco parentis, "teknon" es la palabra más apropiada para dirigirse a los adultos no parientes (DICKEY, 1996: 65-72).

131 RuSSELL, 1980: 123-128.

132 BRENK, 1998: 31-49.

133 Supra., n. 14.

${ }^{134}$ RAMBAUD, 1974: 117; PORTE, 1994: 473. Rambaud apunta que César, con su dictum, estaría "dévoilant l'origine adultere du dernier républicain". Porte comenta que "[...] fils, comme le demande l'usage

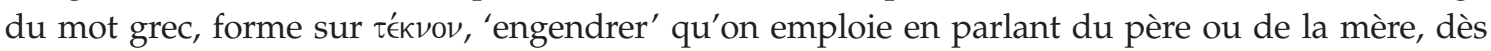
L'Illiade. Plus rare que $\pi \alpha \iota \varsigma$, il conserve mieux que lui l'idée d'une filiation par la chair, et c'est sans doute la raison por laquelle il vint spontanément aux lèvres de César" (PORTE, 1994: 473). Abonan esta tesis, aunque sin justificación filológica, Pelling (2009: 266-267) pero con reservas, y Canfora, si bien matizando que Suetonio recoge la anécdota "[...] por un mero escrúpulo de totalidad", aunque sorprendentemente yerra al justificar su postura, primero, al embarullar la obra de Dión Casio con la Vida de César de Plutarco - pues sostiene que la anécdota está también presente en esta- y, segundo, al señalar que el episodio está presente en la Vida de Bruto (CANFORA, 2000: 361-362). Antes bien, la anécdota del epitafio oral no está presente en la Vida de Bruto presumiblemente porque, según Moles, Plutarco la ignoraba a causa de no haber consultado a Livio. De lo contrario, precisamente por las razones que aduce Canfora de que sí está ("que allí es Bruto el héroe del relato, y la anécdota enfatiza su protagonismo en el asunto, incluso también en su extremo cumplimiento"), Plutarco la habría registrado de haber tenido conocimiento de ella (MoLES, 2017: 182 y 184). 
de que así, por tanto, César estuviera denostándole en su condición de bastardo e incluso censurando a alguien capaz de matar a su propio padre ${ }^{135}$. Adicionalmente, se ha propuesto que César, interrumpido por el fallecimiento, se quedase a mitad de la frase ${ }^{136}$, y de continuar, podría haber concluido: “Tú también, hijo mío, saborearás un día un poder como el mío"; al menos un emperador posterior se manifestó de modo parecido, tal vez citando a César o a algún autor desconocido ${ }^{137}$. Por último, recientemente I. Ziogas ha interpretado el dictum cesariano en clave epigramática funeraria, que en su opinión se refiere a la muerte como destino común de todos los

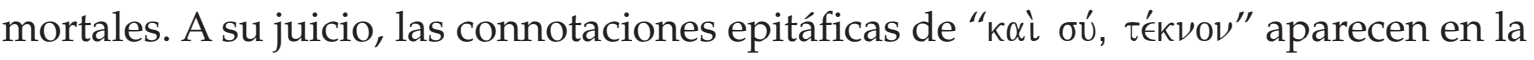
poesía épica, una conexión que otorga una dimensión homérica a las últimas palabras del dictador. La frase de César predeciría la muerte de M. Bruto como consecuencia de su implicación en el cesaricidio, implicación por la que el dictador no estaría ni sorprendido ni decepcionado, y significaría, por tanto, “Tú también, hijo, morirás". La creencia greco-romana consistente en que un hombre moribundo puede prever el futuro -comenta Ziogas- otorgaría a las últimas palabras de César una autoridad profética ${ }^{138}$.

\section{CONCLUSIONES}

En conclusión, resulta innegable un claro viraje en lo que a la visión sobre Julio César se refiere por parte de R. Syme a partir de 1960. Lejos ahora de reflexionar fundamentalmente sobre el senado de César, acerca de las intenciones últimas del gran prohombre romano y sobre el tratamiento de César en la literatura augústea, el polígrafo oxoniense se ve atraído en esta última etapa de su carrera especialmente -amén de por D. Bruto- por dilucidar la sempiterna cuestión de la paternidad César-Bruto. The Roman Revolution significó, en lo que a la investigación sobre

${ }_{135}$ StRAUSS, 2016: 168. A. Cuatrecasas, por su parte, contempla las posibilidades que defienden por un lado Rambaud y Porte, y por otro Strauss, sin decantarse por ninguna (CUATRECASAS, 2003: 107, n. 75).

${ }^{136}$ El Prof. A. Duplá, en cambio, me ha comentado que esta explicación le resulta bastante inverosímil, ya que, a su juicio, la interrupción no fue fulminante, sino que el dictador estaba siendo atacado y era consciente de ello.

${ }^{137}$ ARNAUD, 1998; WOODMAN, 2006. Los autores que propugnan esta tesis beben en buena medida de Suetonio (Galb., 4, 1), aunque existen varias versiones de la anécdota. Tácito, Dión y Josefo atribuyen la profecía no a Augusto sino a Tiberio, y, por tanto, la sitúan en una época ulterior a la mencionada por Suetonio (la infancia de Galba). Tácito $(A n n ., 6,20)$ la ubica durante el consulado de Galba (33 d.C.); Dión (57, 19), hacia sus esponsales; Josefo (Ant., 18, 216), en fin, no informa de una etapa precisa, y también, a su juicio, Tiberio no trasladó estas palabras a Galba, sino a sus amigos, al ver que el futuro emperador se acercaba. A. J. Woodman prefiere interpretar que el dictum de César vendría a decir que "'Your turn will come' and was to be understood by Brutus as forecasting that one day he would suffer a violent death similar to that which he was now inflicting upon Caesar", en el sentido de empatizar la predicción implícita de los peligros del poder (WOODMAN, 2006: 183-184).

${ }^{138}$ ZIOGAS, 2016. 
César se refiere, la culminación de buena parte de los estudios que el autor neozelandés había llevado a cabo durante la segunda mitad de la década de los 30 -artículos, como señalaba Birley, Vorarbeiten para su magnum opus ${ }^{139}$. Tras sentar cátedra merced a lo que Yavetz ha denominado como uno de los fundamentos conceptuales de su más influyente monografía, a saber, la demolición de la "Monarquía Helenística" de Meyer ${ }^{140}$, Syme cambia totalmente de tercio.

A su juicio, M. Bruto no resultaría ser vástago de César. Como señala el propio autor, esta ficción romántica responde, en primer lugar, a la aventura que mantuvieron César y Servilia y, en segundo lugar, al duende que el supuesto y dramático vínculo paternofilial entre César y Bruto ha despertado en dramaturgos y literatos en general e incluso en especialistas en el campo de la psicología de tiempos posteriores, todo ello en detrimento de la verdad desnuda; La Divina comedia de Dante y los ensayos psicohistóricos en clave freudiana resultan buenos ejemplos en este sentido. Adicionalmente, como hemos venido desarrollando, para el profesor británico las cronologías más probables de los nacimientos tanto de César (100 a.C.) como de M. Bruto (85 a.C.) coadyuvarían todavía más a descartar la paternidad. En general, como hemos comprobado, la historiografía posterior a Syme, salvo aisladas explicaciones como las de M. Rambaud o D. Porte, ha coincidido con el profesor neozelandés.

No sería tampoco, por tanto, cuestión de esterilidad, como apuntara Balsdon. Syme, en una sugerente comparación anacrónica que probablemente tenga su origen en los intereses investigadores que había mostrado el historiador neozelandés en su delicioso Colonial Elites. Rome, Spain and the Americas (Oxford, 1958), parangona a César y sus oficiales con Cortés y Pizarro y sus respectivos hombres en el Nuevo Mundo: en otras palabras, el acceso por parte del prohombre romano y de su entourage más íntimo a las princesas de los diferentes reinos clientes bañados por el Mare Nostrum, habría, de alguna manera, monopolizado la descendencia de César, aunque también sus célebres adulterios con diferentes matronas romanas, prácticas que dificultan -si no imposibilitan- sobremanera determinar la posible descendencia del dictador.

Por último, en relación al escepticismo que inspiraba a Syme el dramático epitafio oral cesariano, probablemente nadie pueda jamás proponer una explicación absolutamente satisfactoria, y resulta estéril avanzar por el campo minado de las conjeturas. Ahora bien, ateniéndonos a la especulación razonable, los estudios posteriores han constatado, en primer lugar, que seguramente César no dijese nada a ese respecto, y el episodio se inventaría a posteriori, y que, en segundo lugar, de ser cierto el suceso, el significado o, cuando menos, la interpretación del dictum en todo caso no estaría vinculado con ninguna alusión o referencia a la paternidad efectiva de César respecto de M. Bruto.

\footnotetext{
139 BIRLEY, 1999: xiii.

140 YaveTZ, 1990: 25. El otro, según Yavetz, sería la "diarquía” de Mommsen.
} 


\section{BIBLIOGRAFÍA}

AFRICA, T. W. (1978), “The Mask of an Assassin: A Psychohistorical Study of M. Junius Brutus", The Journal of Interdisciplinary History, nº 4, vol. 8, 599-626.

AGUDO, R. Mª (trad.) (1992), Vidas de los doce césares, vol. I, Madrid.

AILOUD, H. (ed.) (1930), Suetone. Vies des douze Césars. Tome I, César Auguste, Paris.

ALFÖLDY, G. (1979), “Reseña de R. Syme (1979), Roman Papers, ed. E. Badian, vols. I-II, Oxford", American Journal of Ancient History, n' 4, 167-185.

- (1983), "Sir Ronald Syme, 'Die Römische Revolution' und die deutsche Althistorie", Sitzungsb. Heidelb. Akad. Wiss. Phil-hist. Klasse, 5-42.

ALONSO TRONCOSO, V. (1990), “Desesperadamente ajeno: Sir Ronald Syme y The Roman Revolution", Estudios Clásicos, nº 97, 41-64.

ARCE, J. (1994), “Sir Ronald Syme: la historia romana”, Revista de Occidente, n 152, 37-48.

- (2010), "Prólogo", en R. Syme, La revolución romana, 2a ed., trad. A. Blanco, Barcelona (1 $1^{\text {a }}$ ed. ing., 1939), VII-XVIII.

ARNAUD, P. (1998), “'Toi aussi, mon fils, tu mangeras ta part de notre pouvoir'. Brutus le Tyrant?", Latomus, no 57, 61-71.

BADIAN, E. (1959), "Caesar's cursus and the Intervals between Offices", The Journal of Roman Studies, n 49, 81-89.

- (1967), "Reseña de Cicero. Scripta Quae Manserunt Omnia. Fasc. 4. Brutus by Cicero and E. Malcovati; Cicero. Brutus by Cicero and A. E. Douglas", The Journal of Roman Studies, n 57 , vol. 1, 223-230.

— (1979), "Introduction", en R. Syme, Roman Papers, ed. E. Badian, vol. I, xi-xiii, Oxford.

- (1990), “Reseña de Ch. Meier (1982), Caesar, Berlin”, Gnomon, no 62, vol. 1, 22-39.

- (2009), "From Iulii to Caesar", en M. Griffin (ed.), A Companion to Julius Caesar, 11-22, Oxford.

BALSDON, J. P. V. D. (1958), "The Ides of March", Historia: Zeitschrift für Alte Geschichte, $\mathrm{n}^{\circ}$ 7, vol. 1, 80-94.

— (1960), "Reseña de H. Volkmann (1958), Cleopatra: A Study in Politics and Propaganda, trad. T. J. Cadoux, London", The Classical Review, n 10, vol. 1, 68-71.

BIRLEY, A. R. (1999), “Editor's Introduction”, en R. Syme, The Provincial at Rome and the Balkans, xi-xx, Exeter.

BOWERSOCK, G. W. (1980), "The Emperor of Roman History", The New York Review of Books, $\mathrm{n}^{\circ}$ 27, 06.03.80, 8-13.

— (1994), "Ronald Syme 1903-1989", Proceedings of the British Academy, n 84, 539-563.

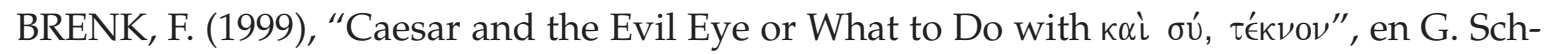
meling y J. D. Mikalson (eds.), Qui miscuit utile dulci: Festschrift Essays for Paul Lachlan MacKendrick, 1-14, Wauconda.

BROUGHTON, T. R. S. (1986), The Magistrates of the Roman Republic, vol. III, Atlanta. 
BUTLER H. E. y CARY, M. (1927), Suetoni Tranquilli Divus Iulius, Oxford.

BYNUM, E. (1897), Das Leben des M. Iunius Brutus bis auf Caesars Ermordung, Halle.

CABRERO, J. (2004), Julio César: el hombre y su época, Madrid.

CANFORA, L. (1991), Ideologías de los estudios clásicos, trad. Ma del M. Linares, Madrid (1 ${ }^{\mathrm{a}}$ ed. it., 1980).

- (2000), Julio César: un dictador democrático, $2^{\text {a }}$ ed., trads. X. Garí y A. Ares, Barcelona (1 ${ }^{\text {a }}$ ed. it., 1999).

CARCOPINO, J. (1933), "Sur la date de la naissance de César", Comptes rendus / Académie des inscriptions et belles-lettres, 377-378, Paris.

- (1934a), "La royauté de César et l'empire universal", Points de vue sur l'impérialisme romain, 89-155, Paris.

- (1934b), "La naissance de Jules César et les surprises d'une élection consulaire", Mélanges Joseph Bidez, I, 41-42, Bruxelles.

- (1947), Les secrets de /a correspondance de Ciceron, vol. II, Paris.

- (1961a), Profils des conquérants, Paris.

- (1961b), "La royauté de César et l'empire universal", Les étapes de l'imperialisme romain, 118-173, Paris.

CARY, M. (1932), "Rome in the Absence of Pompey", en S. A. Cook, F. E. Adcock y M. A. Charlesworth (eds.), The Cambridge Ancient History. IX: The Roman Republic 13344 B.C., 475-504, London.

CHAMBRY, E. y FLACELIÈRE, R. (eds.) (1975), Plutarque. Vies. Tome IX: Alexandre-César, Paris.

- (1978), Plutarque. Vies. Tome IX: Dion-Brutus, Paris.

CRAWFORD, M. H. (1969), Roman Republican Coin Hoards, London.

CUATRECASAS, A. (ed.) (2003), Suetonio. Vida de los doce césares, Madrid.

D'ANTÒ, V. (1957), "Sviste ed errori nei dati cronologici di Suetonio e di altri biografi minori", Annali della Facoltà di Lettere Di Napoli, nº 6, 117-143.

- (1975), "Sviste ed errore nei dati cronologici di Suetonio e di altri biografi minori", Annali della Facoltàdi Lettere e Filosofia dell'Università di Napoli, nº 7, 117-143.

DEMOUGIN, S. (2000), "Les acteurs secondaires dans la Révolution Romaine de R. Syme", en A. Giovannini (ed.), Entretiens sur L'Antiquité classique, XLVI: La Révolution Romaine après Ronald Syme: Bilans et perspectives, 73-112, Vandoeuvres-Gèneve.

DE SANCTIS, G. (1934), "La data della nascita di G. Cesare”, Rivista di Filologia e Istruzione Classica, $\mathrm{n}^{\circ} 12,550-551$.

DEUTSCH, M. E. (1914), “The Year of Caesar's Birth”, Transactions of the American Philological Association, $\mathrm{n}^{\circ} 45,17-28$.

DICKEY, E. (1996), Greek Forms of Address: From Herodotus to Lucian, Oxford.

DOUGLAS, A. E. (ed.) (1966), Cicero: Brutus, Oxford. 
DRUMANN, W. (1837-1838), Geschichte Roms in seinem Übergange von der republikanischen zur monarchischen Verfassung; oder, Pompeius, Caesar, Cicero und ihre Zeitgenossen nach Geschlechtern und mit genealogischen Tabellen, vols. III-IV, Königsberg.

DRUMANN, W. y GROEBE, P. (1906-1908), Geschichte Roms in seinem Übergange von der republikanischen zur monarchischen Verfassung; oder, Pompeius, Caesar, Cicero und ihre Zeitgenossen nach Geschlechtern und mit genealogischen Tabellen, $2^{\mathrm{a}}$ ed., vols. III-IV, Leipzig (1 $1^{\text {a }}$ ed., 1837).

DUBUISSON, M. (1980), “Toí aussi, mon fils!", Latomus, nº 39, 881-890.

DUVAL, M. (1991), “D. Junius Brutus: mari ou fils de Sempronia?”, Latomus, nº 50, vol. 3 , 608-615.

ETIENNE, R. (1973), Les Ides de Mars. L'assassinat de César ou de la dictature?, Paris.

FERRERO, G. (1906), Grandezza e decadenzza di Roma, vol. I, Milano.

FREEMAN, P. (2009), Julio César: la biografía del hombre más importante de la antigua Roma, Barcelona ( $1^{\text {a }}$ ed. ing., 2008).

GAGO, M. (en prensa), “La relación entre Julio César y Décimo Bruto de cara a los idus de marzo: la visión de Sir Ronald Syme y su recepción historiográfica", Revista de Historiografía.

GALLI, F. (ed.) (1981), M. Tullio Cicerone. Brutus, Milano.

GELZER, M. (1918), Realencyclopädie der classischen Altertumswissenschaft, vol. 10.1, Stuttgart, s.v. M. Iunius Brutus, nr. 53, colls. 973-1020.

- (1921), Caesar: der Politiker und Staatsman, Stuttgart-Berlin.

- (1968), Caesar: The Politician and Statesman, $6^{\mathrm{a}}$ ed., trad. P. Needham, Cambridge (Mass.) (1 ${ }^{a}$ ed. al., 1921).

GOLDSWORTHY, A. K. (2007), César: la biografía definitiva, $2^{\mathrm{a}}$ ed., trad. T. Martín, Madrid ( $1^{\text {a }}$ ed. ing., 2006).

GRIFFIN, J. (2009), "Shakespeare's Julius Caesar and the Dramatic Tradition”, en M. Griffin (ed.), A Companion to Julius Caesar, 371-398. Oxford.

GRIFFIN, M. (2009), “Introduction”, en Id. (ed.), A Companion to Julius Caesar, 1-8, Oxford.

GROEBE, P. (1907), “Das Geburtsjahr des M. Brutus”, Hermes, nº 42, vol. 2, 304-314.

- (1918), Realencyclopädie der classischen Altertumswissenschaft, vol. 10.1, Stuttgart, s.v. C. Iulius Caesar, nr. 131, colls. 186-259.

GUGEL, H. (1970), “Caesars Tod (Sueton, Div. lul., 81. 4-82. 3). Aspekte zur Darstellungskunst und zum Caesarbild Suetons", Gymnasium, n' 77, 5-22.

HARRIS, W. V. (2017), “Governing class. New papers from a distinguised historian”, The Times Literary Supplement, 11-8-2017, 32.

HELlGOUARC’H, J. (ed.) (1982), Velleius Paterculus. Histoire romaine. Livre II, vol. II, Paris.

HOLMES, T. R. (1917), “Was Caesar born in 100 or in 102 B.C.", Journal of Roman Studies, $\mathrm{n}^{\mathrm{o}} 7,145-152$. 
- (1923), The Roman Republic and the Founder of the Empire, vol. I, Oxford.

LAST, H. (1944), “Cinae Quater Consvlis”, The Classical Review, no 58, vol. 1, 15-17.

LINTOTT, A. (2009), “The Assassination”, en M. Griffin (ed.), A Companion to Julius Caesar, 72-82, Oxford.

MACMULLEN, R. (1966), Enemies of the New Order, Cambridge (Mass.).

MALCOVATI, E. (1960), "Per una nueva edizione del Brutus", Athenaeum, no 38, 328-340.

- (ed.) (1970), M. Tulli Ciceronis Scripta quae manserunt omnia, fasc. 4, Brutus, $2^{\mathrm{a}}$ ed., Leipzig (1 $1^{\text {a }}$ ed., 1965).

MARTHA, J. (ed.) (1923), Brutus. Ciceron, Paris.

MARTIN, P. M. (1988), Tuer César!, Bruxelles.

MCLAUGHLIN, M. (2009), "Empire, Eloquence, and Military Genius: Renaissance Italy", en M. Griffin (ed.), A Companion to Julius Caesar, 335-355, Oxford.

MEIER, CH. (1982), Caesar, Berlin.

MEYER, E. (1919), Caesar Monarchie und des Prinzipat des Pompeius. Innere Oeschichte Roms von 66 bis 44 v. Chr., $2^{\text {a }}$ ed., Suttgart-Berlin (1 ${ }^{\text {a }}$ ed., 1918).

- (1922), Caesar Monarchie und des Prinzipat des Pompeius. Innere Oeschichte Roms von 66 bis 44 v. Chr., $3^{\text {a }}$ ed., Suttgart-Berlin (1 ${ }^{a}$ ed., 1918).

MOLES, J. L. (2017), A Commentary on Plutarch's Brutus. With updated bibliographical notes by Christopher Pelling, Histos Supplement, $\mathrm{n}^{\circ}$ 7, Newcasttle Upon Tyne.

MOMIGLIANO, A. (1962), "Introduzione”, en R. Syme, La rivoluzione romana, ix-xv, Torino.

MOMMSEN, TH. (1856), Römische Geschichte, vol. III, Berlin.

- (1887), Römische Staaatsrecht, $3^{\text {a }}$ ed., vol. I, Leipzig (1 $1^{\text {a }}$ ed., 1871).

MÜNZER, F. (1918), Realencyclopädie der classischen Altertumswissenschaft, vol. X.1, Stuttgart, s.v. Iulia, nr. 547, colls. 894-895.

— (1923), Realencyclopädie der classischen Altertumswissenschaft, vol. II A, 2, Stuttgart, s.v. Servilia, nr. 101, colls. 1817-1821.

NAVARRO, A. (ed.) (2010), Macrobio. Saturnales, Madrid.

NIPPERDEY, C. (1864), "Bemerkungen zu den kleinen Schriften des Tacitus (Fortsetzung)", Rheinische Musseum für Philologie, nº 19, 270-292.

- (1865), Die Leges Annales der Römischen Republik, Leipzig.

- (1870), Abhandlungen der phil. hist. Classe des könig. sächs. Gesellschatt der Wissenschatten, Berlin, 3-62.

OPPERMANN, H. (2004), Julio César: la grandeza del héroe, trad. R. P. Blanco, Madrid (1 a ed. al., 1968).

PATERSON, J. (2009), “Caesar the Man”, en M. Griffin (ed.), A Companion to Julius Caesar, 126-140, Oxford.

PELLING, CH. (1979), "Plutarch's Method of Work in Roman's Lives", Journal of Hellenic Studies, $\mathrm{n}^{\circ}$ 99, 74-96. 
- (1997), "Plutarch on Caesar's Fall”, en J. Mossmann (ed.), Plutarch and his Intellectual World, 215-232, London.

- (2009), "Seeing a Roman tragedy through Greek eyes: Shakespeare's Julius Caesar", en S. Godhill y E. Hall (eds.), Sophocles and the Greek Tragic Tradition, 264-288, Cambridge.

- (2011), Plutarch: Caesar, Oxford-New York.

- (2015), "The Rethoric of The Roman Revolution", Syllecta Classica, n 26, 207-247.

PICÓN, V. (ed.) (1998), Suetonio. Vidas de los Césares, Madrid.

PIGANIOL, A. (1927), La conquête romaine, Paris.

PORTE, D. (1994), “La perle de Servilia (note sur la naissance de Marcus Junius Brutus)”, Revue des Études Anciennes, nº 96, 465-484.

RAMBAUD, M. (1974), César, $2^{a}$ ed., Paris (1ª ed., 1963).

RODRÍGUEZ-PANTOJA, M. (ed.) (1996), Cicerón. Cartas II: cartas a Ático, Madrid.

ROYLE, N. (2006), "Julius Caesar and the Democracy to Come", en M. Wyke (ed.), Julius Caesar in Western Culture, 205-229, Malden (Mass.).

RUIZ, A. (ed.) (2014), Historia de Roma. Veleyo Patérculo, Madrid.

RUSSELL, J. (1980), “Julius Caesar's Last Words: A Reinterpretation”, en B. Marshall (ed.), Vindex Humanitatis. Essays in Honour of John Huntly Bishop, 123-128, Armidale.

SALIS, J. F. W. DE (1866), “Date de la naissance de Jules César", Revué Archeologiqué, no 14, $17-22$.

SÁNCHEZ, Ma A. (ed.) (2001), Veleyo Patérculo. Historia Romana, Madrid.

SÁNCHEZ J. P. y GONZÁLEZ, M. (eds.) (2009), Plutarco. Vidas Paralelas, vol. VII, Madrid.

SANTANGELO, F. (2014), "The Triumph of Caesarism. An unfinished book by Ronald Syme", Quaderni di Storia, $\mathrm{n}^{\circ}$ 79, 5-31.

- (2016), "Introduction", Approaching the Roman Revolution: Papers on Republican History, $1-15$, Oxford.

SCHEID, J. (2000), "Ronald Syme et la religion des Romains", en A. Giovannini (ed.), Entretiens sur L'Antiquité classique, XLVI: La Révolution Romaine après Ronald Syme: Bilans et perspectives, 39-72, Vandoeuvres-Gèneve.

SEECK, O. (1901), “Das Geburtsjahr des Marcus Brutus”, Rheinische Musseum für Philologie, $\mathrm{n}^{\circ} 56,631-634$.

- (1907), “Noch Einmal das Geburtsjahr des M. Brutus”, Hermes, no 42, vol. 3, 505-508.

SHIPLEY, F. W. (ed.) (1924), Compendium of Roman history. Velleius Paterculus. Res gestae Divi Augusti, London.

STRAUSS, B. (2016), La muerte de César. El asesinato más célebre de la historia, trad. D. Pereda, Madrid (1 ${ }^{\text {a }}$ ed. ing., 2015).

SUÁREZ, A. M. (1997), “César: ¿un político popular?”, POLIS: Revista de ideas y formas políticas de la Antigüedad Clásica, nº 9, 249-275. 
- (2004), La crisis de la República Romana (133-44 a.C.): la alternativa política de los "populares", Santiago de Compostela.

SUMNER, G. V. (1971), “The Lex Annalis under Caesar (Continued)”, Phoenix, n² 25, vol. 4, 357-371.

- (1973), The Orator's Brutus: Prosopography and Chronology, The Phoenix, Supplementary, vol. 11, Toronto.

SYDENHAM, E. A. (1952), The Coinage of the Roman Republic, London.

SYME, R. (1936), “Reseña de J. Lindsay (1935), The Romans, London”, The Classical Review, $\mathrm{n}^{\mathrm{o}} 50,40-41$.

- (1944), "Reseña de M. Gelzer (1941), Caesar der Politiker und Staatsmann, München”, Journal of Roman Studies, $\mathrm{n}^{\circ}$ 34, 92-103.

- (1955), "Reseña de T. R. S. Broughton (1951-1952)", The Magistrates of the Roman Republic, Vol. I: 509 B.C.-100 B.C.; Vol. II: 99 B.C.-31 B.C., New York, Classical Philology, nº 50, vol. 2, 127-138.

- (1958), Tacitus, Oxford.

- (1960), "Bastards in Roman Aristocracy", Proceedings of the American Philosophical Society, $\mathrm{n}^{\mathrm{o}}$ 104, vol. 3, 323-327.

- (1971), "Bad Trip", The New York Review of Books, n' 27, 1-7-1971, 40-42.

- (1980), "No son for Caesar", Historia: Zeitschrift für Alte Geschichte, no 28, 422-437.

- (1985), "Caesar: Legend, Drama, History", The New York Review of Books, n 31, 1, 28-5-1985, 12-14.

- (1986), The Augustan Aristocracy, Oxford.

- (1988), "Oligarchy at Rome: a Paradigm for Political Science”, Diogenes, n 36, 141, 56-75.

- (1999), "Caesar's Designs on Dacia and Parthia", en Id., The Provincial at Rome, ed. A. R. Birley, 174-192, Exeter.

TAYLOR, L. R. (1941), “Caesar's Early Career”, Classical Philology, n 34, vol. 2, 113-132.

VILLAR, J. A. (ed.) (1995), Tito Livio. Períocas. Períocas de Oxirrinco. Fragmentos. Julio Obsecuente: libro de los prodigios, Madrid.

VIVAS, G. (2012), “La visión de la historia y el método de Sir Ronald Syme en la obra de Géza Alföldy: algunas consideraciones", Espacio, tiempo y forma. Serie II, historia antigua, n 25, 19-38.

— (2017), "Géza Alföldy and Ronald Syme: a case study", Studia Europaea Gnesnensia, n²0, 529-551.

WALTER, G. (1938), Brutus et la fin de la République, Paris.

WALTER, U. (2002), “Der Historiker in Seiner Zeit: Ronald Syme und die Revolution des Augustus", en R. Spielvogel (ed.), Res publica reperta. Fetschrift für J. Bleicken, 137-152, Stuttgart.

WARDE FOWLER, W. (1931), Jules César et la fondation du régime impérial romain, trad. L. Rambert, Paris (1 $1^{\text {a }}$ ed. ing., 1891). 
WHITE, H. (ed.) (1913), Appian's Roman History, London.

WHITE, H. R. E. (1950), Insignia of office as rewards in the Roman Republic: Advancement in Rank under the Roman Republic as a Reward for the Soldier and the Public Prosecutor, Bryn Mawr.

WILKINS, A. S. (ed.) (1903), M. Tulli Ciceronis Rhetorica, Oxford.

WILLIS, I. (1970), Ambrosii Theodosii Macrobii. Saturnalia: apparatu critico instruxit in somnium Scipionis comentarios, Stuttgart.

WISEMAN, T. P. (1998), "Late Syme. A Study in Historiography”, Roman Drama and Roman History, 135-152, Exeter.

WOODMAN, A. J. (2006), "Tiberius and the Taste of Power: The Year 33 in Tacitus", Classical Quarterly, n 59, 175-189.

WYKE, M. (2006), "Caesar, Cinema, and National Identity in the 1910s", en Id. (ed.), Julius Caesar in Western Culture, 170-189, Malden (Mass.).

YAVETZ, Z. (1971), “Caesar, Caesarism, and historians", Journal of Contemporary History, $\mathrm{n}^{\circ}$ 6, vol. 2, 184-201.

- (1983), Julius Caesar and his Public Image, London (1 ${ }^{\mathrm{a}}$ ed. al., 1979).

- (1990), “The personality of Augustus: Reflections on Syme's Roman Revolution", en A. Raaflaub y M. Toher (eds.), Between Republic and Empire: Interpretations of Augustus and his Principate, 21-41, Berkeley-Los Angeles-Oxford.

ZIOGAS, I. (2016), "Famous Last Words: Caesar's Prophecy on the Ides of March", Antichthon, no 50, 134-153.

ZUMPT, A. W. (1874), De Dictatoris Caesaris die et anno natali, Berlin. 